\title{
RECUPERAÇÃO E IMPERMEABILIZAÇÃO UTILIZANDO ÓLEO DE LINHAÇA EM UMA BALAUSTRADA: ESTUDO DE CASO
}

\author{
QUEIROZ, ANNA BEATRIZ RODRIGUES DE \\ Graduanda em Engenharia Civil \\ Universidade Potiguar \\ Rio Grande do Norte; Brasil \\ beatriz.abrq@hotmail.com
}

\author{
MARQUES, MARCOS VINÍCIUS DIAS \\ Graduando em Engenharia Civil \\ Universidade Potiguar \\ Rio Grande do Norte; Brasil \\ mv.vinicius2000@gmail.com
}

\section{CRUZ, CLÁUdiA PATRÍCIA TORRES}

Professora Doutora em Física da Matéria Condensada Universidade Potiguar

Rio Grande do Norte; Brasil

claudiacruz.unp@gmail.com

\author{
SANTOS, KLLEYSON FREITAS DOS \\ Graduando em Engenharia Civil \\ Universidade Potiguar \\ Rio Grande do Norte; Brasil \\ klleysonfreitas2@hotmail.com
}

\author{
SANTOS, RODRIGO RODRIGUES DOS \\ Graduando em Engenharia Civil \\ Universidade Potiguar \\ Rio Grande do Norte; Brasil \\ rodrigorodrigues9798@ hotmail.com
}

\author{
LUCENA, MAURÍLIO DE MEDEIROS \\ Professor Mestre em Engenharia Mecânica \\ Universidade Potiguar \\ Rio Grande do Norte; Brasil \\ mauriliomedeiros@unp.br
}

\section{RESUMO}

Este artigo descreve o desenvolvimento e o estudo de uma mistura que servirá de agente impermeabilizante a ser aplicado nas faces externas de uma balaustrada construída na zona costeira em Natal/ RN. Para esse estudo, foi produzida uma mistura utilizando óleo de linhaça e cal virgem e foram confeccionados corpos de prova em cujas faces externas foi aplicada a mistura. Em seguida, os corpos de prova foram submetidos a testes laboratoriais. Verificou-se, através dos ensaios laboratoriais, que os efeitos da aplicabilidade da mistura nos corpos de prova resultaram na impermeabilização, diminuição e retardamento do processo de desgaste da estrutura. Como o óleo usado na mistura apresenta em sua composição agentes dessecantes tóxicos com alto poder de conservação, a mistura promoveu, de forma satisfatória, o aumento da vida útil dos corpos de prova e, portanto, está apta a ser aplicada nas faces externas da balaustrada. Palavras-chave: óleo de linhaça, cal virgem, patologia, construção civil. balaustrada.

\section{ABSTRACT}

This article describes the development and study of a mixture that will serve as a waterproofing agent to be applied on the external faces of a balustrade built in the coastal area in Natal/ RN. For this study, a mixture was produced using linseed oil and virgin lime and specimens were made in whose external faces the mixture was applied. Then, the specimens were submitted to laboratory test. It was verified, through the laboratory tests, that the effects of the mixture applicability on the specimens resulted in the waterproofing, reduction and delay of the structure's wear process. As the oil used in the mixture presents in its composition toxic desiccant agents with high conservation power, the mixture promoted, in a satisfactory way, the increase of the useful life of the specimens and, therefore, it is able to be applied to the external faces of the balustrade.

Keywords: linseed oil, virgin lime, pathology, construction, balustrade. 


\section{INTRODUÇÃO}

As patologias nas edificações são as principais causas de problemas que comprometem a vida útil das construções (ARIVABENE, 2015). Manifestações patológicas podem ser encontradas de diversas maneiras e aspectos, e com isso entra o papel das normas técnicas para que as manifestações patológicas sejam amenizadas, evitadas e recuperadas quando for o caso (HILLESHEIM, 2016). Os revestimentos de argamassa, especificamente o reboco, e pinturas são ações mais relevantes e recorrentes em manutenções prediais. Isto faz com que estudos sejam desenvolvidos para que essas ações sejam cada vez mais aperfeiçoadas e assim atendam aos requisitos de durabilidade. De acordo com UEMOTO (1997) a intensa ação das intempéries sobre a pintura provoca a degradação desta, alterando características e propriedades das tintas, tais como o aumento da permeabilidade. Em revestimentos de pinturas podem ser manifestadas patologias do tipo descolamento da camada de pintura e defeitos na película (UEMOTO, 1997).

A utilização de óleos vegetais como meio de recuperação está presente desde o início do século XV, um exemplo de uso é o óleo de linhaça, sendo utilizado como óleo secativo em tintas artificiais (FONSECA, 2009). O óleo de linhaça é um dos aditivos mais usados no passado, exclusivamente no período romano, devido sua intensa utilização com finalidade de reduzir a permeabilidade à água em argamassa (CECHOVA et al., 2008). A impermeabilização das estruturas pela aplicação da mistura de cal virgem e óleo de linhaça possui satisfatório desempenho que, segundo EIRIS (2006) os valores de absorção de água são reduzidos a partir da utilização do óleo de linhaça. Em seus estudos sobre incorporação de biopolímeros em construção de terra, EIRES (2012) concluiu que o óleo de linhaça influenciou o aumento da resistência à compressão do corpo de prova de terra em relação ao corpo de prova de referência.

CECHOVA (2009) verificou a influência da adição do óleo de linhaça em argamassas e observou que o óleo de linhaça em pequena porcentagem pode promover a redução da porosidade bem como o tamanho desses poros. Por outro lado, com uma maior porcentagem de adição do óleo de linhaça a porosidade tende a aumentar. Quanto a resistência mecânica, observa-se esta também aumenta com pequena porcentagem de adição e diminui com uma maior adição percentual do óleo. É importante destacar que os resultados e dados obtidos por outros autores tornam-se difícil de se comparar uma vez que as mudanças provocadas pela adição de um óleo vegetal em um revestimento qualquer irá variar de acordo com as condições de cada situação, como por exemplo, o tipo de óleo, tempo de mistura, condições ambientais, o tipo de revestimento utilizado entre outros fatores.

A adição desse componente natural em revestimentos do tipo acabamento, no caso pinturas, busca melhorar aspectos relacionados com a durabilidade do sistema, bem como aplicar um tipo de revestimento que proporcione a restauração em certos casos. A mistura de óleo de linhaça com tintas a base de cal visa a impermeabilização da peça a qual foi aplicada a mistura, reduzindo assim o ataque de agentes externos devido a agressividade do ambiente. Com isso, a inserção de uma adição natural que promove resultados discutíveis permite a realização de estudos para que se verifique a sua utilização por comprovação de um desempenho satisfatório. A partir disso, este estudo tem por objetivo a utilização de óleo de linhaça como adição em pinturas de cal-virgem, visando impermeabilização de uma balaustrada localizada na Av. Getúlio Vargas em Natal/RN para melhorar a durabilidade do elemento estrutural.

\section{METODOLOGIA}

Iniciou-se através da revisão da literatura onde foram pesquisados estudos relacionados com a abordagem. Os procedimentos foram divididos em duas etapas: em laboratório e na balaustrada em estudo. De forma esquematizada, os procedimentos realizados neste estudo estão representados na Figura 1. 


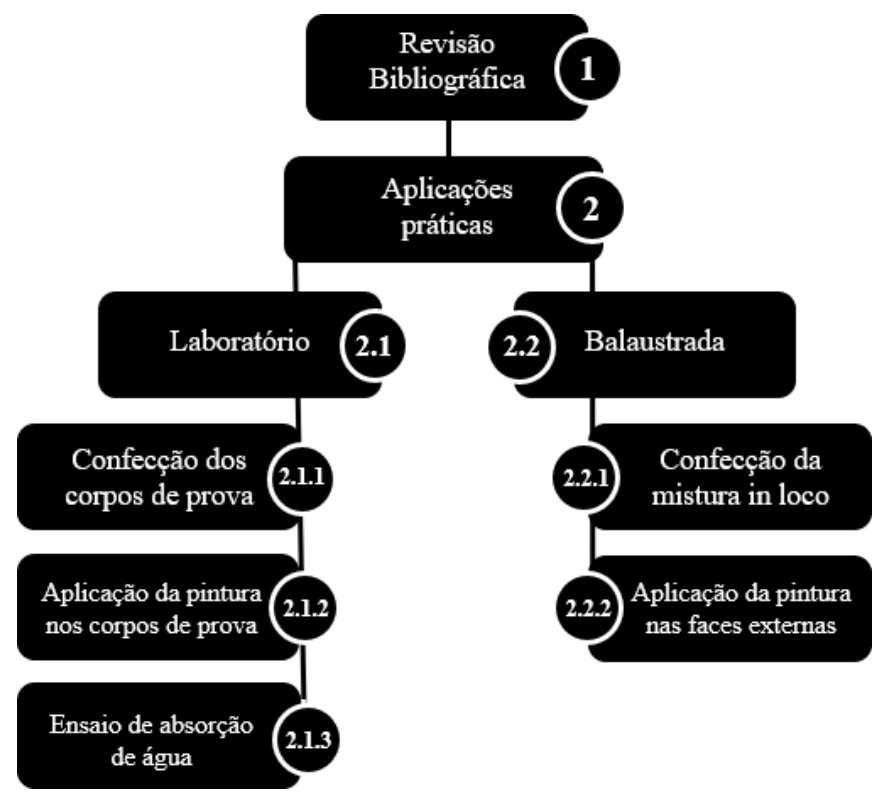

Figura 1: Fluxograma de procedimentos metodológicos.

Fonte: Autores, 2019.

Na etapa de laboratório, foram moldados corpos de prova prismáticos com dimensões de 40mm x 40mm x 160mm de graute. A escolha do graute se justifica pelo fato de que a estrutura em questão foi recuperada com aplicação de graute, logo, os ensaios laboratoriais estariam relacionados com a estrutura real. Foram moldados seis corpos de prova, que foram desmoldados e posteriormente submetidos ao período de cura de 7 dias. Após a desmoldagem foi realizada a pintura de três corpos de prova com a mistura, e três corpos de prova adotados como referência para possibilitar comparação dos dados obtidos nos ensaios. Os corpos de prova moldados podem ser observados na Figura 2.

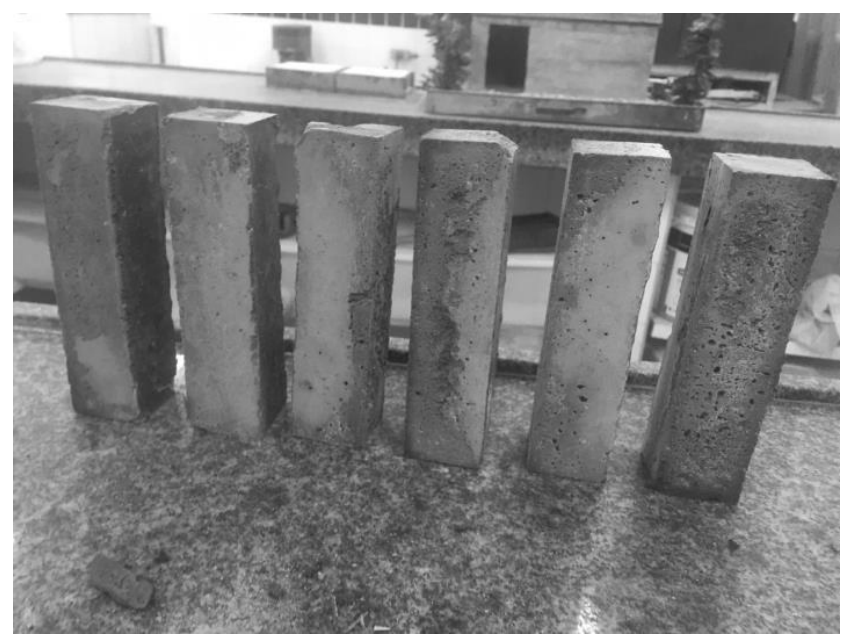

Figura 2: Corpos de prova para estudos laboratoriais. Fonte: Autores, 2019.

A mistura utilizada para a pintura teve composição de $50 \mathrm{ml}$ de óleo de linhaça, 3,5 $\mathrm{kg}$ de Cal virgem e aproximadamente 61 de água (o processo de hidratação da cal virgem consome bastante água, e com isso não foi possível ter precisão na quantidade de água utilizada). O preparo da mistura pode ser observado na Figura 3. 


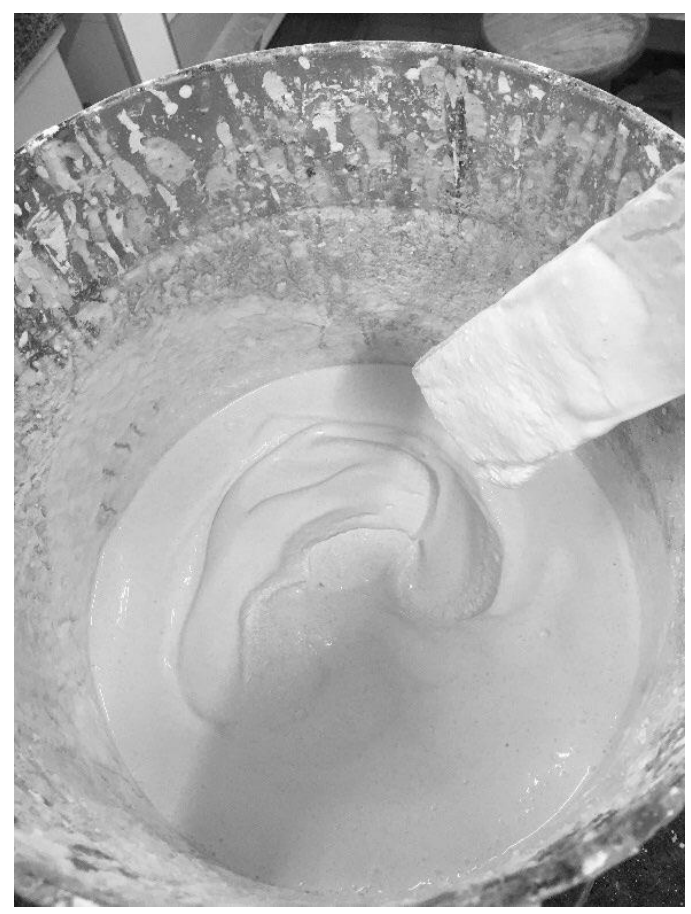

Figura 3: Processo de confecção da mistura. Fonte: Autores, 2019.

Em seguida, os corpos de prova foram pintados e submetidos à secagem, conforme Figura 4.

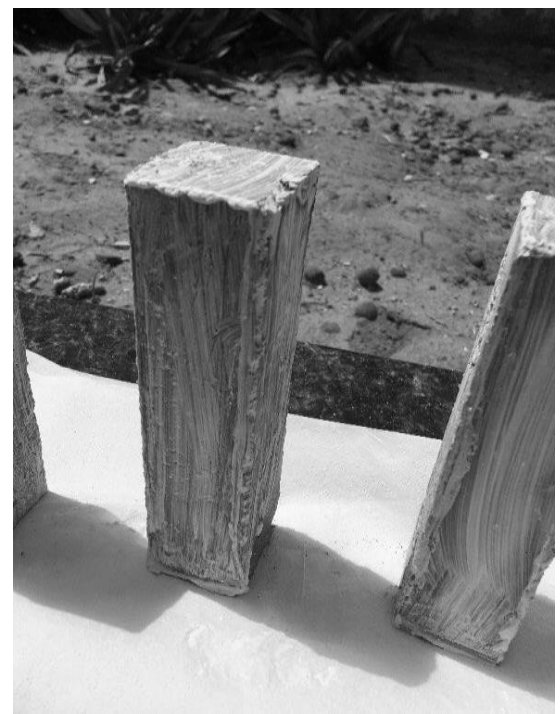

Figura 4: Corpos de prova pintados com a mistura. Fonte: Autores, 2019.

Após a secagem da tinta foi realizado do ensaio de absorção de água para observar os níveis de absorção dos corpos de prova de graute, tendo como referência a NBR 15259:2005, sendo este ensaio adaptado para a situação em estudo, visto que para esse tipo de material é inexistente alguma norma técnica.

Os corpos de prova foram posicionados com uma das fases quadradas sobre o suporte dentro do recipiente onde foi adicionada a água até alcançar $5 \mathrm{~mm}$ acima da fase em contato com a água. Os tempos escolhidos para o ensaio foram, em minutos, os quadrados dos números naturais $0,1,2,3,4,5,6,8,9,10$ e 11, de forma a obter intervalos de tempo cada vez maiores entre as medidas consecutivas. Em cada intervalo de tempo os corpos de prova foram levemente enxugados para retirada do excesso de água e pesados para aferição da massa. 
Após o término dos procedimentos de laboratórios, iniciaram-se os procedimentos realizados na balaustrada, localizada na Avenida Getúlio Vargas, em Natal/RN. Diferente da etapa de laboratório, no local de estudo foi realizada a preparação da superfície com limpeza, lixamento e retirada de camadas de tintas já existentes na estrutura.

Foi preparada a mistura de $200 \mathrm{ml}$ de óleo de linhaça, 13,5 kg de Cal virgem e aproximadamente 201 de água. Na Figura 5 pode observar a preparação da mistura in loco.

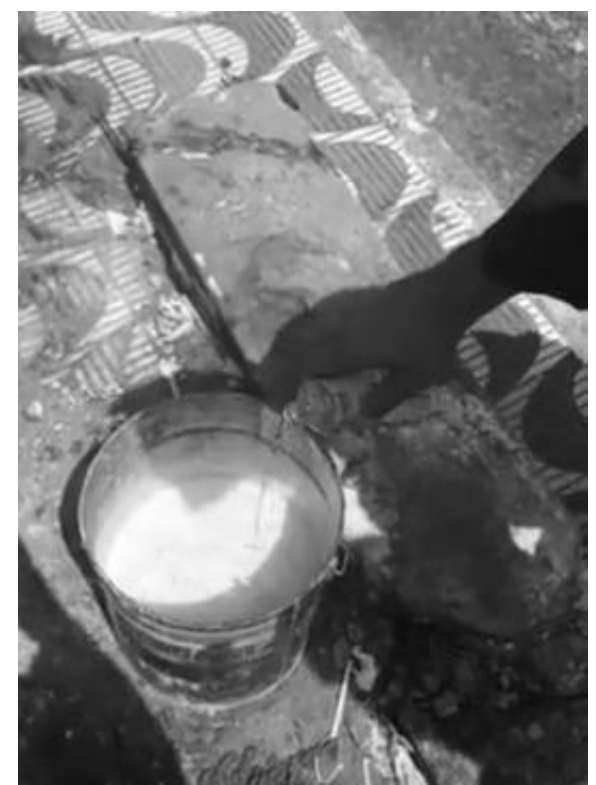

Figura 5: Preparação da mistura para aplicação na balaustrada. Fonte: Autores, 2019.

Em seguida, foi feita a aplicação da mistura com pincel convencional com duas demãos em todas as faces externas da estrutura conforme as Figuras 6.

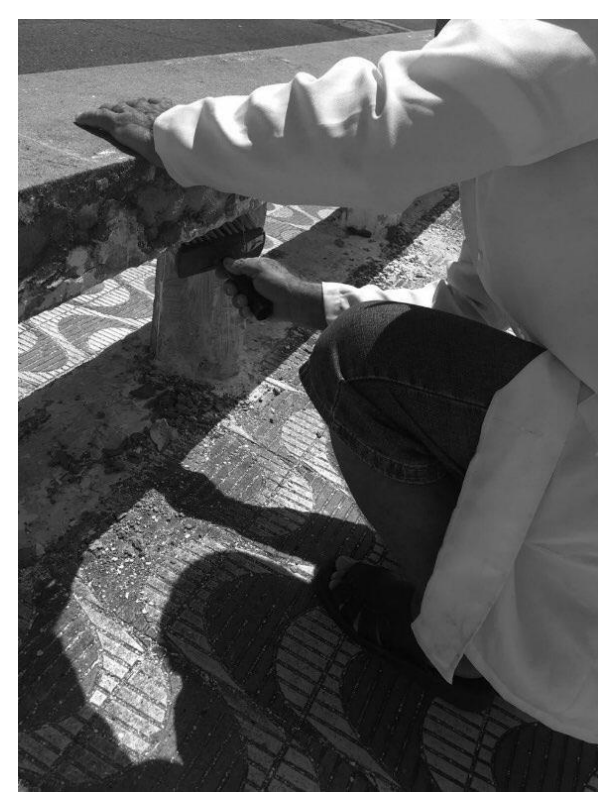

Figura 6: Aplicação da mistura com pincel. Fonte: Autores, 2019. 
Com a finalização da pintura nas faces externas, observado na Figura 7, já foi possível verificar os aspectos estéticos recuperados mediante o comparativo anterior das peças.

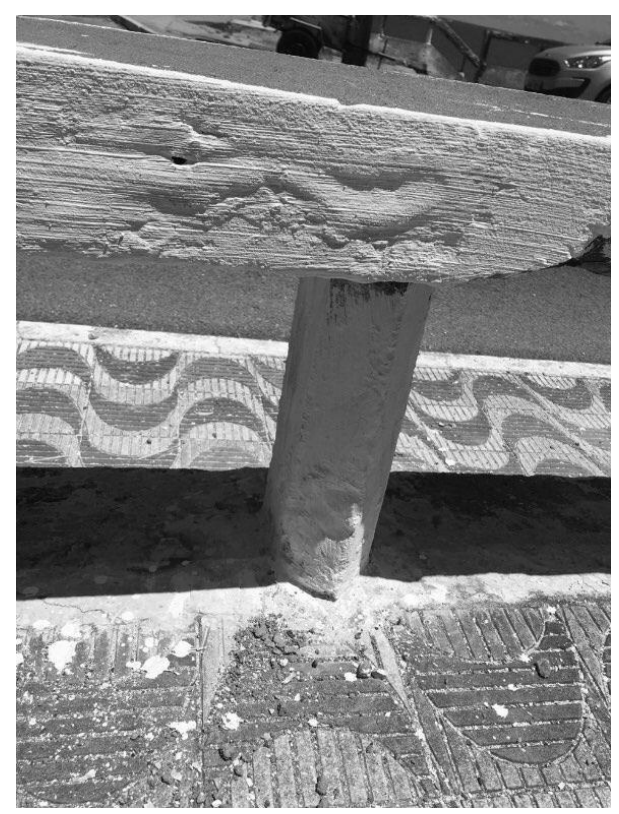

Figura 7: Pintura nas faces externas. Fonte: Autores, 2019.

\section{RESULTADOS}

Com a realização do ensaio de absorção por capilaridade, adaptado para o caso do graute, foi possível verificar a absorção de água em determinados tempos. Para fins de resultados, foi levado em conta a quantidade de água absorvida pelos corpos de prova secos após entrarem em contato com água em um intervalo de tempo de 121 minutos. Esses dados podem ser observados no gráfico da Figura 8.

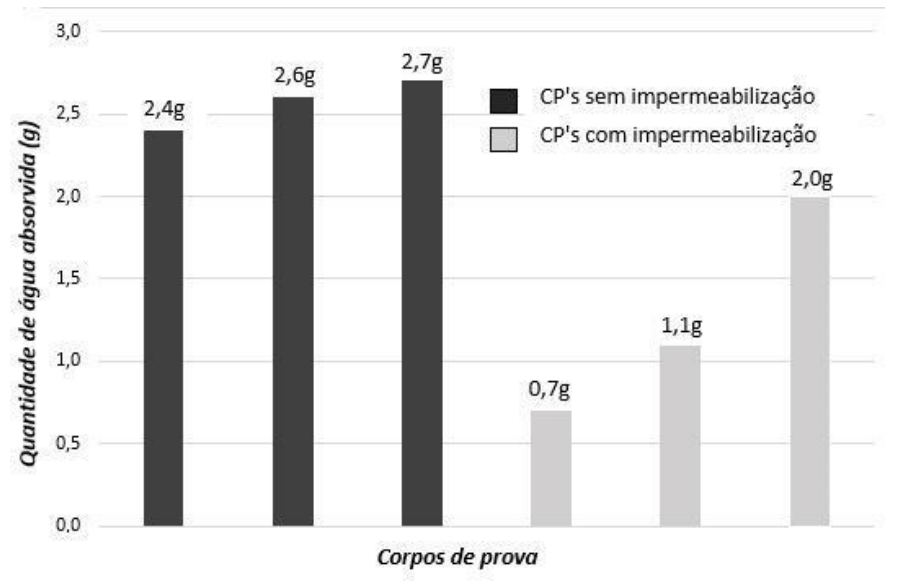

Figura 8: Resultado do ensaio de capilaridade após 121 minutos. Fonte: Autores, 2019. 
Assim, foi possível verificar a quantidade de água absorvida, em gramas, no intervalo de 121 minutos para os corpos de prova com e sem pintura. Com isso constatou-se que os corpos de prova de referência absorveram maior quantidade de água em relação aos corpos de prova pintados com a mistura de cal virgem e óleo de linhaça. Isso significa que a pintura tem influência na absorção de água, reduzindo assim os valores em relação aos corpos de prova que não foram submetidos a pintura. De acordo com FONSECA (2009), o poder secativo do óleo está diretamente ligado às insaturações que lhe conferem reatividade química, principalmente com o oxigênio do ar.

\section{CONCLUSÕES}

A idealização da mistura de óleo de linhaça com cal virgem buscou melhorias quanto a proteção e durabilidade das peças submetidas à esta pintura. Além disso, a mistura de tinta possibilitou alterar os aspectos estéticos da estrutura, bem como reduzir a agressão por fatores externos devido a agressividade do ambiente.

A ausência de normas técnicas que trata do assunto em questão dificultou na realização e obtenção dos resultados dos ensaios, principalmente pela utilização do material de recuperação utilizado na balaustrada e pelo tipo de verificação necessária para o estudo.

A partir do ensaio de absorção de água por capilaridade pode-se inferir que houve uma melhora, mas outros ensaios, tais como: aceleração da degradação e comportamento frente a ciclos de variação de umidade precisam ser feitos para que tal resultado possa ser confirmado. Além disso, é importante destacar que o intervalo de tempo em que foi realizado o ensaio de absorção pode influenciar o resultado do ensaio realizado, bem como sua adaptação.

É necessário que em estudos futuros utilizem ensaios que possam verificar demais propriedades, além da utilização de materiais convencionais como argamassas e concreto, para que assim seja verificado se a adição de óleo de linhaça em mistura com cal virgem pode ser utilizada com uma pintura restauradora, impermeabilizante e se está influencia na durabilidade da estrutura.

\section{REFERÊNCIAS}

ABNT, ASSOCIAÇÃO BRASILEIRA DE NORMAS TÉCNICAS. NBR 9779. Argamassa e concreto endurecidos — Determinação da absorção de água por capilaridade. Brasil, 2012.

ARIVABENE, Antonio Cesar. Patologias em estruturas de concreto armado: Estudo de caso. Revista Especialize On-line IPOG, Goiânia, 2015, 3.10: 1-22.

CECHOVA, E.; PAPAYIANNI, I.; STEFANODOU, M. The influence of lindseed oil on the properties of limebased mortars. In: International conference HMC. 2008.

CECHOVA, E. The Effect of Linseed Oil on the Properties of Lime-based Restoration Mortars (Dissertação de doutorado), University of Bologna, 2009. Disponível em: <http://amsdottorato.unibo.it/id/eprint/2267>. Acesso em 15 de janeiro de 2020 .

DA FONSECA, Marcelo Marques; YOSHIDA, Maria Irene. Comportamento térmico do óleo de linhaça natural e envelhecido artificialmente. Educação \& Tecnologia, 2009, 14.2.

EIRES, R. Materiais não convencionais para uma construção sustentável utilizando cânhamo, pasta de papel e cortiça. 2006. PhD Thesis. Disponível em: <http://hdl.handle.net/1822/7053>. Aceso em 13 de janeiro de 2020.

EIRES, R. M. G. Construção em terra: desempenho melhorado com incorporação de biopolímeros. Tese (Doutorado em Engenharia Civil - Materiais de Construção) - Escola de engenharia - Universidade do Minho, Portugal. 2012. Disponível em: <http://repositorium.sdum.uminho.pt/handle/1822/21010>. Acesso em 16 de janeiro de 2020.

FONSECA, Marcelo Marques da; YOSHIDA, Maria Irene. Análise térmica do óleo de linhaça natural e oxidado. Vértices, 2009, 11.1: 61-76. 
HILlESHEIM, Camila, et al. PATOLOGIAS NA CONSTRUÇÃo CIVIL: estudo de caso para a Entidade Beneficente. Maiêutica-Engenharias, 2016, 2.1.

UEMOTO, K. L.; AGOPYAN, V. Durabilidade de revestimentos à base de polímeros. in Workshop Durabilidade das construções, São Leopoldo, RS.: UNISINOS, Jun./Jul. 1997. p. 55-63 
